\title{
A Novel Optimal Design for Electrical Transmission Pylons Considering Effects of Electromagnetic Fields on Human Body
}

\author{
Ali Asadollahi ${ }^{1} \quad$ Mohsen Assili $^{2}$ \\ ${ }^{1}$ MSc. Student, Power Engineering Department, Faculty of Electrical Engineering, Shahrood University of Technology, \\ Shahrood, Iran \\ Asadollahi78@gmail.com \\ ${ }^{2}$ Assistant Professor, Power Engineering Department, Faculty of Electrical Engineering, Shahrood University of \\ Technology, Shahrood, Iran \\ $\underline{\text { m.assili@shahroodut.ac.ir }}$
}

\begin{abstract}
:
This paper investigates relation and influence between electromagnetic fields generated by high voltage transmission lines and human health. A novel pylon with optimal phase arrangement through possible configuration is presented by optimizing a multi-objective cost function consists of the electric field, magnetic field, and the segments cost. For comparison between current pylons and the proposed pylon, the human model is placed below high voltage overhead lines and then electromagnetic fields and current density is simulated. Electromagnetic fields from overhead lines are calculated by using PLS-CADD and PLS-TOWER software based on Maxwell's method. The human body is modeled by the Finite Element Method (FEM) in MATLAB. Results show that the new pylon decreases electromagnetic fields distribution on the human body and this pylon also mitigates the right-of-way width by its special position of phase conductors.
\end{abstract}

Keywords: Electric and Magnetic Fields, Optimization, $400 \mathrm{kV}$ Transmission lines, Human Health, Phase Arrangement.

Article Type: Research paper

Submission date: 01, April. 2018

Conditional Acceptance date: 08, Aug. 2018

Acceptance date: 15, Feb. 2020

Corresponding author: $M$. Assili

Corresponding author's address: Power. Eng. Dep., Elec. Eng. Faculty, Shahrood Uni. Of Tech. Shahrood, Iran. 


\section{Introduction}

Developing urban and constructing transmission lines have concerned increasingly about their effects on human health and the environment. There are strong electric and magnetic fields (EMF) around high voltage transmission lines, soawarenessand prevention of its risks are necessary. For over 40 years, scientists have been researchingthe possible risks of EMF on human health. Until now, hundreds of research and epidemiological studies have been carried out and their results have been used.[1-3].

Nowadays, each country has certain guidelines for protection againstelectromagnetic fields and several recommendations and instructionshave been providedbythe international organizations like WHO (World Health Organization), IEEE (Institute of Electrical and Electronics Engineers) and ICNIRP (International Commissions on Non-Ionizing Radiation Protection). The recent research according to ICNIRP (which issimilar to guidelines in Iran) and other studies propose that the electric field should belessthan 5 to 10 $\mathrm{kV} / \mathrm{m}$ and the magnetic field shouldlimited to 100 to 500 $\mu \mathrm{T}$. [4-7].

The aim of this paper is introducing and designing a new pylon for overhead transmission lines with a different arrangement of phases that has less impact of electromagnetic fields on human and environment.

In this paper, a $400 \mathrm{kV}$ - double circuit pylon is used for simulation. It is modeled by using PLS-TOWER, PLSCADD software for electromagnetic simulation and Finite Element Method from MATLAB software for current density calculation on the human body.

\section{Method of EMF Calculation}

There are many methods for calculating the electric and magnetic fields. For Simulating of EMF,we usedPLSCADD software.All of EMF calculations in PLS-CADD are based on EPRI red book methodology [8, 9] that the following is explained.

\subsection{Calculation of Electric Field}

The electric field is calculated using the method of Maxwell's potential coefficient [10]. It is done for a singlephase and will be extended to the threephases. In this method bundle conductors are replacedwith a single conductor and equivalent diameter $\left(r_{i}\right)$ may determine by applying the following expression (Eq. 1) [11, 12].

$r_{i}=\sqrt[m]{m r_{m g} R^{m-1}}$

$R=\frac{d}{2 \sin \left(\frac{\pi}{m}\right)}$

Where $r_{m g}$ is the radius of sub-conductors within the bundle, $\mathrm{m}$ is the total number of sub-conductor within one bundle, $R$ is the radius of the bundle and $d$ is the distance between the adjacent conductors.
In this method, at first, matrix $[q]$ is calculated using the matrix $[v]$ and Maxwell's potential coefficient matrix $[p]$ as shown Eq.3.

$$
[q]=[p]^{-1}[v]
$$

For overhead lines,composed of parallel conductors $(i, j \ldots)$ and plane and Maxwell's potential, coefficient matrix $[\mathrm{p}]$ is determinedby Eq.4 and Eq.5.

$P_{i i}=\frac{1}{2 \pi \varepsilon} \ln \left(\frac{2 y_{i}}{r_{i}}\right)$

$P_{i j}=\frac{1}{2 \pi \varepsilon} \ln \left[\frac{\left(x_{i}-x_{j}\right)^{2}+\left(y_{i}+y_{j}\right)^{2}}{\left(x_{i}-x_{j}\right)^{2}+\left(y_{i}-y_{j}\right)^{2}}\right]^{\frac{1}{2}}$

Where $x_{i}$ and $x_{j}$ are horizontal coordinates of conductors and $y_{i}$ and $y_{j}$ are heights of conductors above the ground.

Solving Eq.3, which determines the charge of each conductor, the electrical field at a point $\mathrm{N}$ of coordinate $\left(x_{N}, y_{N}\right)$ is calculated by Eq.6 using its image relative to the ground surface.

$\bar{E}_{i}=E_{x, i} \bar{u}_{x}+E_{y, i} \bar{u}_{y}$

$\bar{u}_{x}$ and $\bar{u}_{y}$ are unit vectors, $E_{x, i}$ and $E_{y, i}$ are calculated using the Eq. 7 and Eq. 8.

$$
\begin{aligned}
& E_{x, i}= \frac{q_{i}\left(x_{N}-x_{i}\right)}{2 \pi \varepsilon\left[\left(x_{N}-x_{i}\right)^{2}+\left(y_{N}-y_{i}\right)^{2}\right]} \\
&-\frac{q_{i}\left(x_{N}-x_{i}\right)}{2 \pi \varepsilon\left[\left(x_{N}-x_{i}\right)^{2}+\left(y_{N}+y_{i}\right)^{2}\right]} \\
& E_{y, i}= \frac{q_{i}\left(y_{N}-y_{i}\right)}{2 \pi \varepsilon\left[\left(x_{N}-x_{i}\right)^{2}+\left(y_{N}-y_{i}\right)^{2}\right]} \\
&-\frac{q_{i}\left(y_{N}+y_{i}\right)}{2 \pi \varepsilon\left[\left(x_{N}-x_{i}\right)^{2}+\left(y_{N}+y_{i}\right)^{2}\right]}
\end{aligned}
$$

$E_{x}$ and $E_{y}$ are resulted by adding horizontal and vertical components $E_{x, i}$ and $E_{y, i}$ for all conductors $(i, j, \ldots)$ as shown by Eq. 9 and Eq.10 :

$E_{x}=\sum_{i} E_{x, i}$
$E_{y}=\sum_{i} E_{y, i}$

and the magnitude of the field vector is defined by Eq.11:

$E_{N}=\sqrt{E_{x, N}^{2}+E_{y, N}^{2}}$

The field is spinning and describing anelliptical trajectory in the coordinate plane $(x-y)$ and the maximum of the electrical field is half of the biggest diameter of the ellipse.

\subsection{Calculation of Magnetic Field}

The magnetic field of overhead lines is calculated assuming line conductors to be paralleled above flat 
ground. The magnetic field is the sum of all magnetic fields resulted fromthe current of phases and is obtained by Eq.12 [8-11].

$\bar{B}_{N}=\frac{\mu}{2 \pi} \sum_{i} \frac{\bar{l}_{i} \times \bar{r}_{i N}}{r_{i N}^{2}}=\frac{\mu}{2 \pi} \sum_{i} \frac{i_{i}}{r_{i N}} \bar{\emptyset}_{i N}$

$\bar{r}_{i N}$ is the unit vector of the vectorwhich relates point $\mathrm{N}$ to point $\mathrm{i}$ and that isdetermined by Eq.13.

$r_{i N}=\sqrt{\left(x_{N}-x_{i}\right)^{2}+\left(y_{N}-y_{i}\right)^{2}}$

$\bar{\emptyset}_{i N}$ is the unit vector that isthe product of the current vector and position vector. It is calculated by Eq.14.

$\bar{\emptyset}_{i N}=\frac{y_{N}-y_{i}}{r_{i N}} \bar{u}_{x}+\frac{x_{N}-x_{i}}{r_{i N}} \bar{u}_{y}$

\section{Introduction of Lattice Tower}

Thelow height lattice pylon has $35 \mathrm{~m}$ height $(11 \mathrm{~m}$ shorter than standard lattice pylons) with $7 \mathrm{~m}$ length in the base of the tower. This pylon has two cross arms with $21 \mathrm{~m}$ and $30 \mathrm{~m}$ heightabove the ground. The larger arm has a length of $29.2 \mathrm{~m}$ and the length of the lower arm is $17.8 \mathrm{~m}$. These pylons are used for standard conductor span of $310 \mathrm{~m}$ andalso are designed for 30degrees in maximum deviations. Dimensions of the tower are shown in Fig. 1 [13].

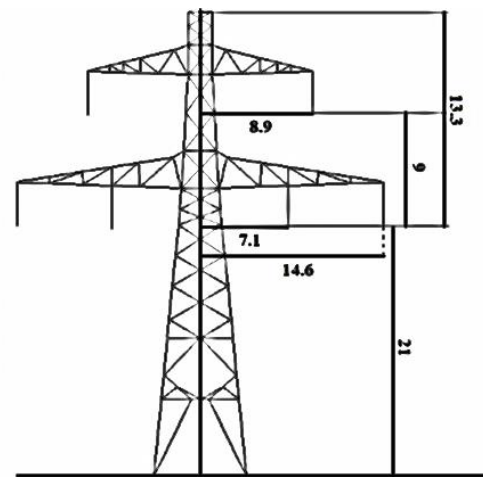

Fig. 1. Dimensions of low height lattice pylon

\section{Definitionof Simulation Characteristics}

\subsection{Conductor}

Choosing the suitable conductor is considered so important in designing transmission lines and for distributing of electric and magnetic fields [14]. In this paper, ACSR (Aluminum Conductor Steel Reinforced) conductor is applied for transmission line.Characteristics of ACSR conductor are presented in Table. 1.
Table.1.Characteristicsof ACSR conductor [15]

\begin{tabular}{|c|c|c|}
\hline & Code Name & curlew \\
\hline $\begin{array}{c}\text { Nominal } \\
\text { diameter of } \\
\text { wires }\end{array}$ & No./m m & $54 / 3.51$ \\
\hline $\begin{array}{c}\text { Overall } \\
\text { Diameter }\end{array}$ & $\mathrm{mm}$ & 31.59 \\
\hline $\begin{array}{c}\text { Nominal } \\
\text { Area }\end{array}$ & $\mathrm{mm} 2$ & 522.51 \\
\hline $\begin{array}{c}\text { Approximate } \\
\text { Weight }\end{array}$ & $\mathrm{kg} / \mathrm{km}$ & 1977.6 \\
\hline $\begin{array}{c}\text { Breaking } \\
\text { Load }\end{array}$ & $\mathrm{KN}$ & 153.90 \\
\hline $\begin{array}{c}\text { Nominal DC } \\
\text { Resistance } \\
\text { at } 20^{\circ} \mathrm{C}\end{array}$ & $\mathrm{ohm} / \mathrm{km}$ & 0.0553 \\
\hline $\begin{array}{c}\text { Current } \\
\text { Rating }(*)\end{array}$ & $\mathrm{A}$ & 716 \\
\hline
\end{tabular}

\subsection{Technical Characteristics of Overhead line}

Calculation for the $400 \mathrm{kV}$ overhead lines have been performed at the pre-fault continuous rating of a twin Curlew conductor bundle that spaced $400 \mathrm{~mm}$ with 3000Amps in each circuit. The nominal voltage is $400 \mathrm{kV}$ and the electric and magnetic fields have beenconsideredat $1.8 \mathrm{~m}$ above the ground. All spans would have a minimum conductor design clearance to ground of $9 \mathrm{~m}$ and the transmission line has untransposed phasing arrangement. Fig. 2 shows phases arrangement for considered transmission line by PLS-CADD software. Phase differences are also specified with their colors. Simulation has been done for flat ground.

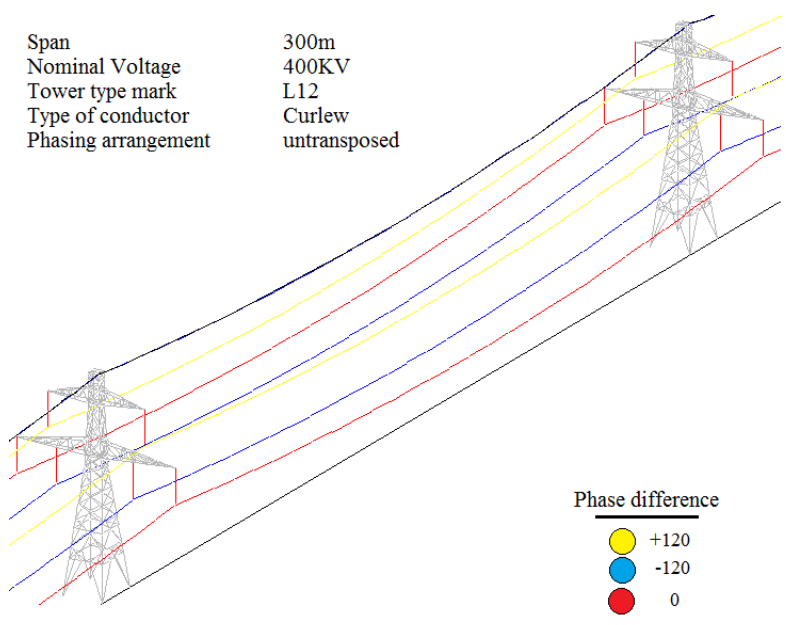

Fig. 2. Spotting towers in transmission lines by PLS-CADD 


\section{Simulation Results for EMF below Power Transmission Lines}

The electric and magnetic fields of low height lattice pylon based on EPRI red book methodology [8] are simulatedby using Pls-Cadd software.The results of the simulation are shown in Fig. 3 and Fig. 4. Table. 2 shows the maximum of the electric and magnetic field below thetower.

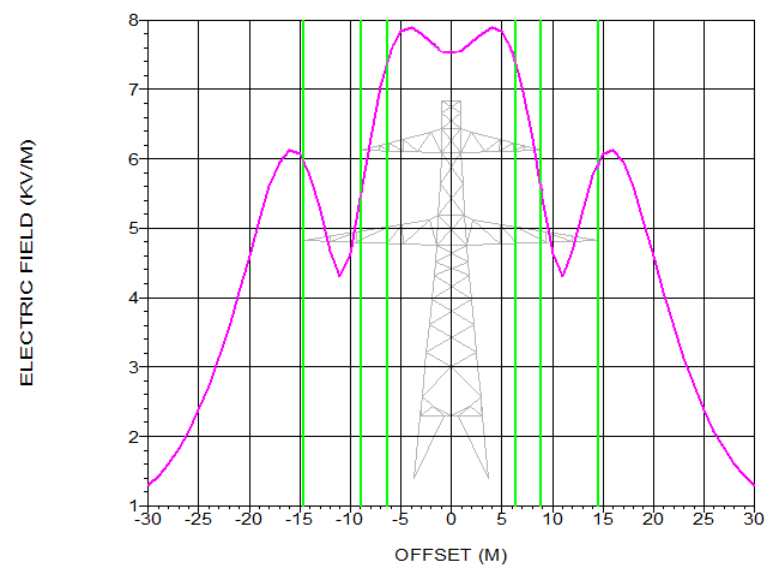

Fig. 3. Simulation results for electric field under low height tower $(1.8 \mathrm{~m}$ above ground)

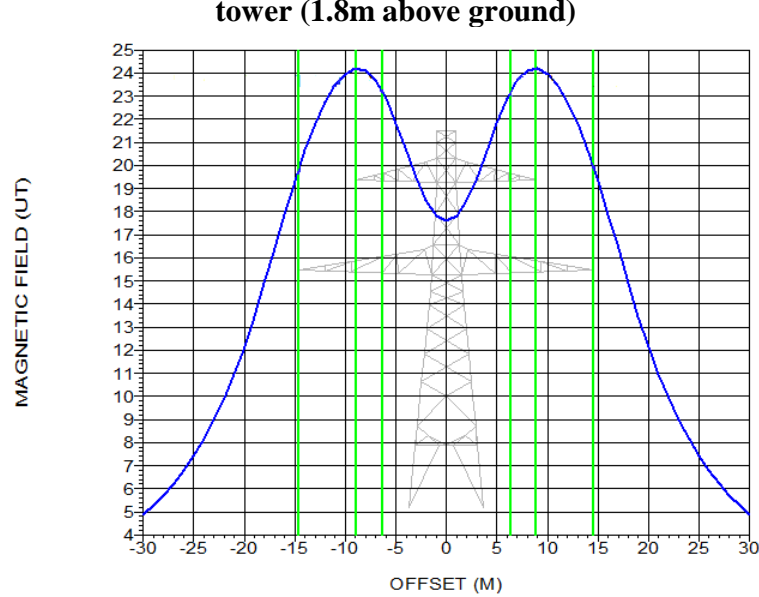

Fig. 4. Simulation results for magnetic field under low height tower(1.8m above ground)

Table. 2.Maximum of electric and magnetic fields

\begin{tabular}{|c|c|c|}
\hline Type of field & $\begin{array}{c}\text { Electric field } \\
(\mathrm{KV} / \mathrm{m})\end{array}$ & $\begin{array}{c}\text { Magnetic field } \\
(\mu \mathrm{T})\end{array}$ \\
\hline $\begin{array}{c}\text { Maximum } \\
\text { field }\end{array}$ & 7.891 & 24.21 \\
\hline
\end{tabular}

\section{Introduction of a New Model}

\subsection{Optimizationof Phase Arrangement}

Nowadays many arrangements for overhead power linesare designed [16-18]. In the introduced case, the optimization goal is to find such an arrangement of phase conductors that the tower height, as well as electromagnetic fields from overhead power lines,become minimal.

\subsection{Multi-objective Optimization}

Non-dominated sorting genetic algorithm (NSGA) is a multi-objective optimization algorithm for solving various problems proposed by Srinivas and Deb in 1994 [19-21].

This paper introduces an optimization solution based on NSGA-II technique to reduce the electromagnetic fields together with cost by rearranging the conductors. The model considers the objective function of the electric field $\mathrm{E}$, the magnetic field $\mathrm{B}$ and the segment cost SC.

The formulation of optimization is shown in the following:

$\operatorname{Min} \bar{Z}=[E(x, y), B(x, y), S C(x, y)]$

Subject to:

$E<E_{\text {ICNIRP }}$

$B<B_{\text {ICNIRP }}$

$8<X, Y<20$

The segment cost is as follows:

$S C=\sum_{i=1}^{n}\left[\frac{h_{i}}{h_{\max }}+\frac{\text { Strain }-s p_{i}}{\text { Strain }-s p_{\max }}\right]$

Where $h_{i}$ is the height of the conductor above the ground and Strain - $s p_{i}$ is the strain on the segments of the structure due to loading. Strain $-s p_{\max }$ isassumed $1000 \mathrm{~N}$.

The steps of the optimization problem by NSGA-II is described below:

i) Generate an initial population $\eta_{\text {pop }}$ and maximum number of generation $\eta_{\text {ger }}^{\max }$.

ii) Evaluate objective function E, B, and SC.

iii) Determine its rank and calculate the crowding distance.

iv) Runa tournament selection by considering the rank values and the crowd distance.

v) Apply a cross over and mutation operator for the new population.

vi) Combine the initial and new population to maintain elitism.

vii) Replace the current population based on the rank and the crowd distance.

viii) Repeat step "iv" until the maximum of iterations reached.

However, B values (order of micro) are smaller than $\mathrm{E}$ values (order of kilo), the weight factor $\mathrm{E}$ and $\mathrm{B}$ are assumed to be equal. Input values for simulation were previously defined in section 4.2 . 


\subsection{Pareto Optimal Front}

For this Multi-objective optimization, the quality of a solution is determined based on the concept of dominance criterion. The non-dominated set of the entire feasible decision space defines the Pareto optimal solution.

The algorithm was simulated using MATLAB software. Results of calculation were obtained after 18 iterations.

Fig. 5 shows the Pareto optimal set for the value of horizontal and vertical coordinates of conductors above the ground.

The boundary determined by the set of all points mapped from the Pareto optimal solution defines the Pareto optimal front.

Fig. 6 shows the value of the fitness functions electromagnetic and segment cost in the final population.

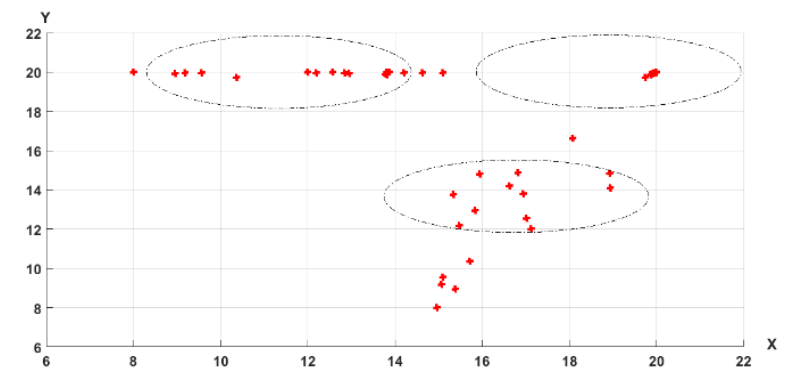

Fig. 5. Pareto optimal solution after 18 iteration

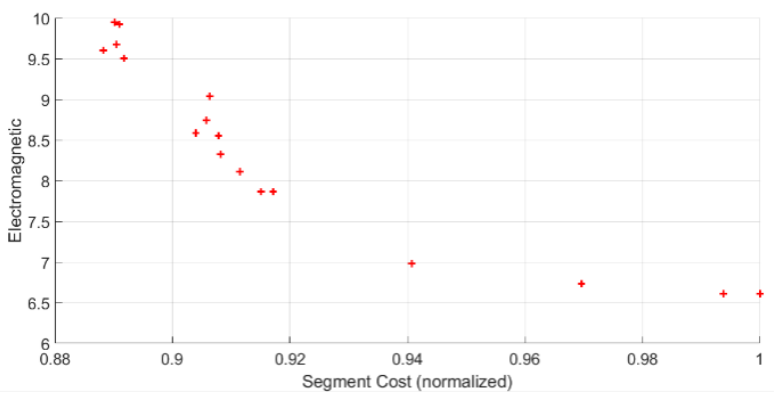

Fig. 6. Pareto front after 18 iteration

The results of Pareto front represents optimal phase arrangement oftransmission line based on minimal values of electromagnetic and material cost, specified by dash line.

\subsection{Introduction of New Tower}

In order to simplify comparison, the new pylon has been chosen similar to that of the low height lattice design. Fig. 7 shows the characteristics of the new pylon [22-23] and Fig. 8 shows phases arrangement for the new pylon in transmission lines.

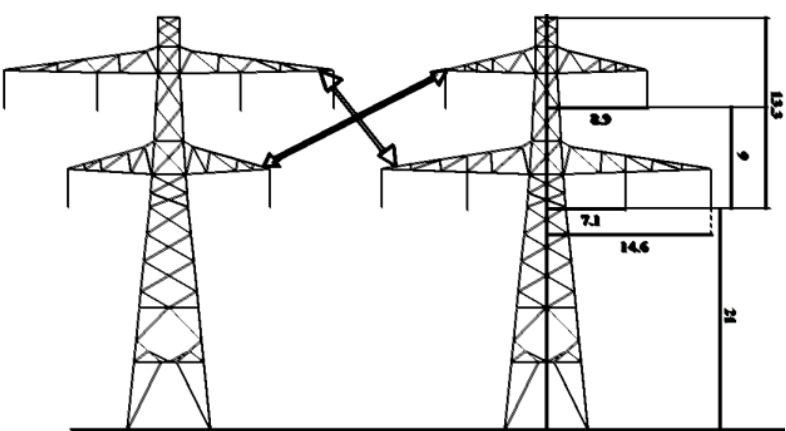

Fig. 7. Dimensions of new pylon (left side)

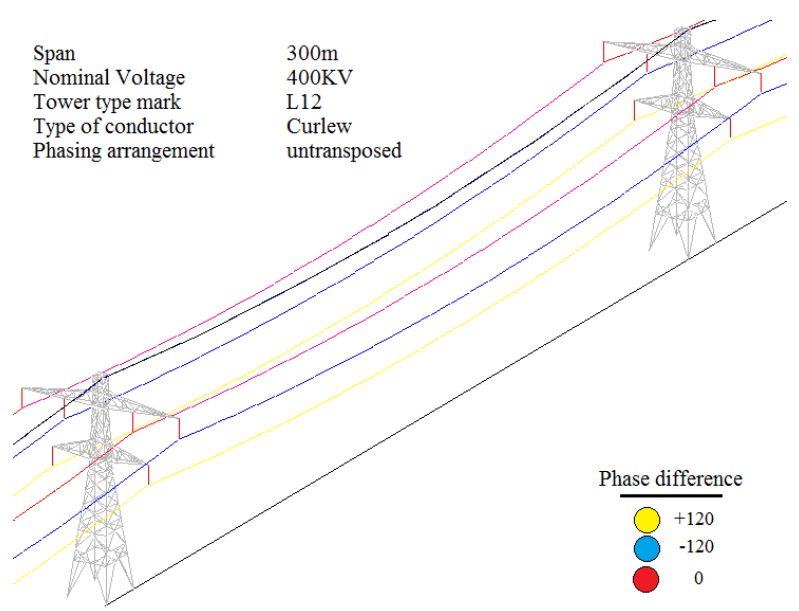

Fig. 8. Spotting new towers in transmission lines by PLS-CADD

\section{Simulation of EMF}

Electric and magnetic fields of new pylon have been calculated and the results of the simulation shown in Fig. 9 and Fig. 10. Table. 3shows the maximum of electric and magnetic fields for the tower.

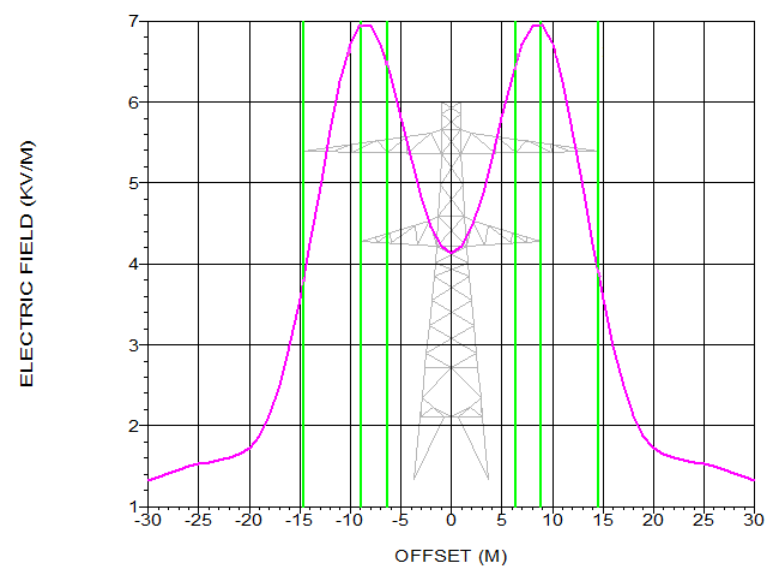

Fig. 9. Simulation for electric field of new pylon 


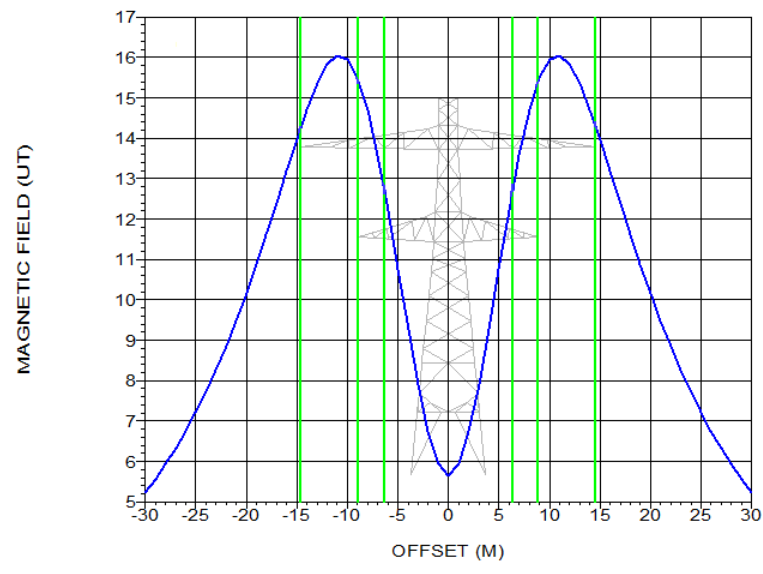

Fig. 10. Simulation for magnetic field of new pylon

Table. 3. Maximum of electric and magnetic fieldsfor new pylon

\begin{tabular}{|c|c|c|}
\hline Type of field & $\begin{array}{c}\text { Electric field } \\
(\mathrm{KV} / \mathrm{m})\end{array}$ & $\begin{array}{c}\text { Magnetic field } \\
(\mu \mathrm{T})\end{array}$ \\
\hline $\begin{array}{c}\text { Maximum } \\
\text { field }\end{array}$ & 6.948 & 16.05 \\
\hline
\end{tabular}

\section{Loading Analysis of Pylon Structure}

A pylon is exposed to various loads. The loads affect the weight and the stress in the membersof the tower. There are specific formulas to determine these loads [24].

In this case, three types of loading conditions have been simulatedfor the pylon: a) High wind, b) Heavy ice and c) Broken wire.

To simplify, loads are modeled on threedifferent directions whichareTransverse, Vertical and Longitudinal.The towers have been analyzed by PLSTOWERsoftware.Input data and then results for loading conditions have been represented in Table 4 and Table 5.

Graphically, Fig. 11 shows the results of static loading analysis obtained by PLS-TOWER.
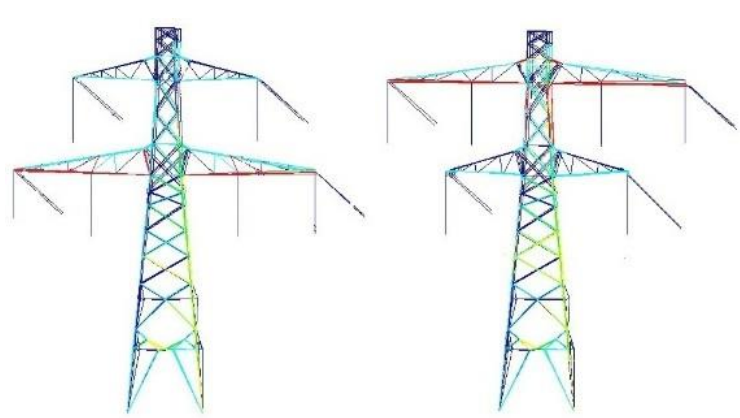

Fig. 11. Loading analysis for transmission towers by PLSTOWER
Table.4. Loading schedule on transmission towers

\begin{tabular}{|c|c|c|c|c|}
\hline \multicolumn{2}{|c|}{ Loadingscenarios } \\
\hline \multirow{2}{*}{ NO. } & \multirow{2}{*}{$\begin{array}{c}\text { Load } \\
\text { case }\end{array}$} & \multicolumn{3}{|c|}{ Applied loads (daN) } \\
\cline { 3 - 5 } & & Transverse & Vertical & Longitudinal \\
\cline { 3 - 5 } 1 & $\begin{array}{c}\text { High } \\
\text { Wind }\end{array}$ & 1859 & 1463 & 0 \\
\hline 2 & $\begin{array}{c}\text { Heavy } \\
\text { Ice }\end{array}$ & 4213 & 2041 & 0 \\
\hline 3 & $\begin{array}{c}\text { Broken } \\
\text { Wire }\end{array}$ & 2045 & 1609 & 2454 \\
\hline \multirow{3}{*}{} & & & \multicolumn{3}{|c|}{ SHIELD WIRE } \\
\cline { 3 - 5 } & $\begin{array}{c}\text { High } \\
\text { Wind }\end{array}$ & 647 & 308 & 0 \\
\hline 2 & $\begin{array}{c}\text { Heavy } \\
\text { Ice }\end{array}$ & 153 & 947 & 0 \\
\hline 3 & $\begin{array}{c}\text { Broken } \\
\text { Wire }\end{array}$ & 77 & 568 & 2926 \\
\hline
\end{tabular}

Table. 5. Results for effects of loads on tower weight

\begin{tabular}{|c|c|c|}
\hline Type of tower & $\begin{array}{c}\text { Old tower } \\
(\mathrm{KN})\end{array}$ & $\begin{array}{c}\text { New pylon } \\
(\mathrm{KN})\end{array}$ \\
\hline $\begin{array}{c}\text { Maximum } \\
\text { Weight }\end{array}$ & 209.58 & 226.33 \\
\hline
\end{tabular}

\subsection{Height of Tower}

For decreasing electric and magneticfields, the height of the old tower is increased.The relation between $\mathrm{E}$ and $\mathrm{H}$ may be expressed by the following equation(Eq.20)[8]:

$\left(\frac{E_{1}}{E_{2}}\right)=\left(\frac{H_{1}}{H_{2}}\right)^{m}$

Where $E_{1}, E_{2}$ are the maximum electric fields, $H_{l}$, $\mathrm{H}_{2}$ are the minimum height of phases to the ground and $m$ depends on the geometry.

Considering the maximum electric field with delta configuration $7.891 \mathrm{kV} / \mathrm{m}$ for 21 meters height and $m \approx-1.2$ [8], the height of the tower will increase to reducethe maximum electric field to

$H_{1} \approx 21 \times 10^{\frac{1}{-1.2}} \log \frac{6.948}{7.891}=23.35$

To reach the maximum electromagnetic field,increasingheightfor new tower affects the curve ofthe stress and also reduces maximum field at the ground.

Fig. 12 shows that increases in height usually cause decreasingin the electric field critical distance $\left(\mathrm{L}_{\mathrm{C}}\right)$, but the electric field does not change significantly for distances greater than $\mathrm{L}_{\mathrm{C}}$. 


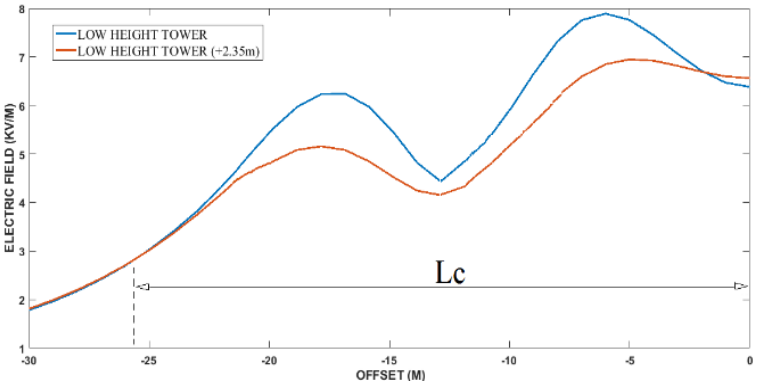

Fig. 12. Effect of height on electromagnetic fields

By increasing $2.35 \mathrm{~m}$ in height of the tower, the weight of the tower increased. Analysis of static loading based on Table. 4 has been shown in Fig. 13.

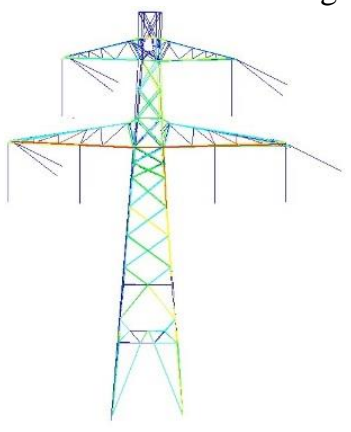

Fig. 13. Analyzing loads on transmission towers by PLSTOWER

Static loading results that maximum weight of the tower increases to $243.8(\mathrm{KN})$.

\section{3D finite Element Method}

For analyzing the electrical field on the human cerebral cortex, in this paper, three-dimensional (3D) numerical computations of electric field have been done by finite element method(FEM)[25], [26]. The previous sections results of electromagneticfields of the transmission line have been directly used in these calculations.

The electrostatic Laplace equation is established as follows [27], [28].

\section{$\nabla .(\sigma \nabla V)=0$}

Where $\sigma$ is electrical conductivity and $\mathrm{V}$ is electric voltage.

The surface mesh is composed of four layers (scalp, outer skull, inner skull, cortical surface). The head model consists of 13,914 nodes and 80.592 elements while the cortical surface contains 25,945 nodes and 52,052 triangles element. It takes 33 seconds to compute electric field on the cortical surface with an Intel ${ }^{\circledR} \operatorname{core}^{\mathrm{TM}}$ i54200M CPU@2.50 GHz.

\subsection{Current Density Induced in Human Head}

The current density induced by an electric field generated by a magnetic field can be determined using the following equations [27], [29]: $\nabla \times B=j w$

$\nabla \cdot j=0$

$j=\sigma . E$

$j=\pi \cdot r \cdot f \cdot \sigma \cdot B$

Where, $\mathrm{j}$ is current density in $\mathrm{A} / \mathrm{m}^{2}, \mathrm{r}$ is the radial distance from the center of the cylinder to the evaluated electric field $(\mathrm{m})$ and $\mathrm{f}$ is frequency (HZ). The dimensional of the head of a person with a radius $=0.1 \mathrm{~m}$ and body of $0.3 \mathrm{~m}$ and $\sigma=0.2 \mathrm{~s} / \mathrm{m}$ may be seen in Fig. 14 and in Fig. 15.

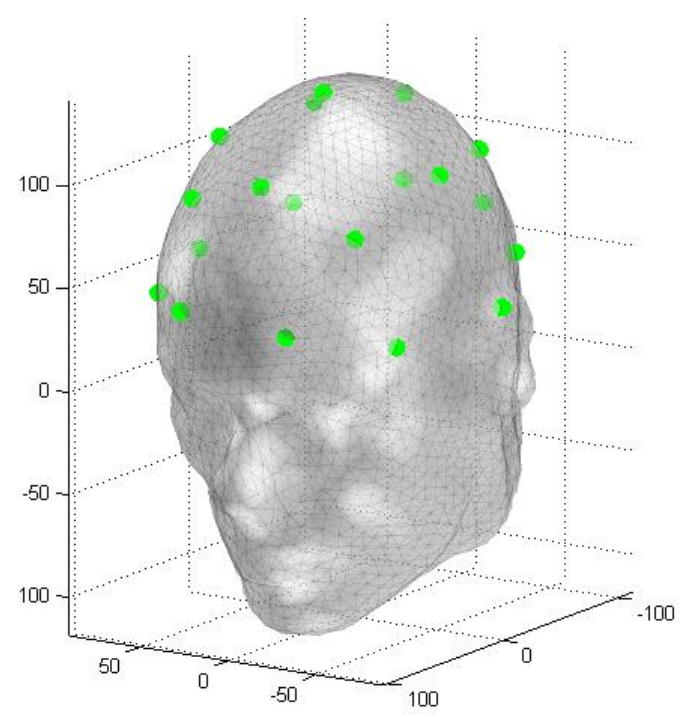

Fig. 14. Dimensions of a human head

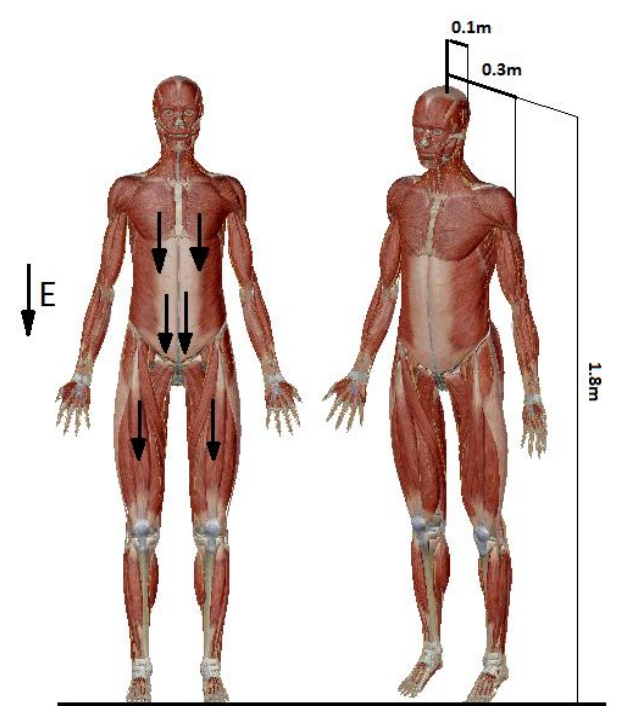

Fig. 15. Direction of electric field and typical dimensions of human body

\subsection{Simulation of Current Density}

For both the low height tower and the new pylon, the results of simulations on the human head and the human body have been presented by Fig. 16 and Table. 6. The distributed electric field has been created by $400 \mathrm{kV}$ double circuit overhead line. 


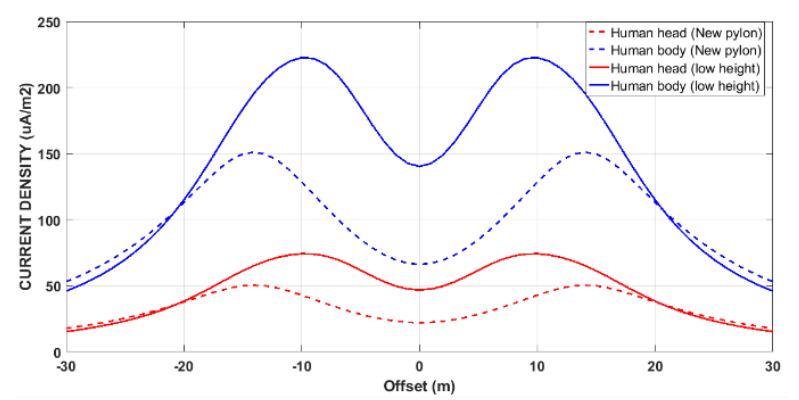

Fig. 16. Simulation current density of low height tower and new pylon by FEM

Table.6. Results of current density

\begin{tabular}{|c|c|c|}
\hline & $\begin{array}{c}\text { Current density } \\
\text { onHuman Body } \\
\left(\mu \mathrm{A} / \mathrm{m}^{2}\right)\end{array}$ & $\begin{array}{c}\text { Current density on } \\
\text { Human Head } \\
\left(\mu \mathrm{A} / \mathrm{m}^{2}\right)\end{array}$ \\
\hline Low height Tower & 228.17 & 76.05 \\
\hline New pylon & 151.26 & 50.42 \\
\hline
\end{tabular}

\subsection{Simulation of Scalp with FEM}

The human head below the high voltage transmission line wasmodeled by finite element method (FEM). For analyzing electric field on the human cerebral cortex, electrode pads are put on the head.For current density simulating we used transcranial directed-current simulation (tDCS) [30-33].

The tDCS is a novel method for the electrical simulation that can modulate cortical excitability of the human brain with transmitting a direct current (DC) through electrode pads attached on the scalp. The tDCS method has been studied in a variety of clinical and research fields [34-36].

Results of the calculation process of FEM have been graphically shown in Fig. 17 for low height lattice and Fig. 18 for the new pylon.

Observing simulation on the human head with $1.8 \mathrm{~m}$ height above ground and $0.1 \mathrm{~m}$ radius of the head, ithas resulted that the new pylon has lower adverse effects than low height lattice tower on human health.

\section{Conclusion}

The aim of this paper was introducing a new pylon with different phases arrangement to improve human health against the high voltage transmission effects.

Using the optimization of phases arrangement, the proposed method decreased the electric and the magnetic fields and induced current density from the overhead line.

By observation of the result of simulations, the following conclusions are drawn:

- Considering the lower and upper value of electric field variations, low height tower has a larger variation $(13.57 \%)$ compared with the new pylon.
- The low height tower has larger variation (51.02\%) compared with the new pylon in the magnetic field.

- Current density on the human body and human head in low height tower has larger variation $(50.84 \%)$ compared with new pylon.

- By increasing the height of low height tower for the same electromagnetic fields as in the new pylon, weight of tower is increased $16.32 \%$.

- Weight of new tower has larger variation (7.99\%) compared with low height tower which by considering electromagnetic fields factor, new configuration is better than old phase arrangement.

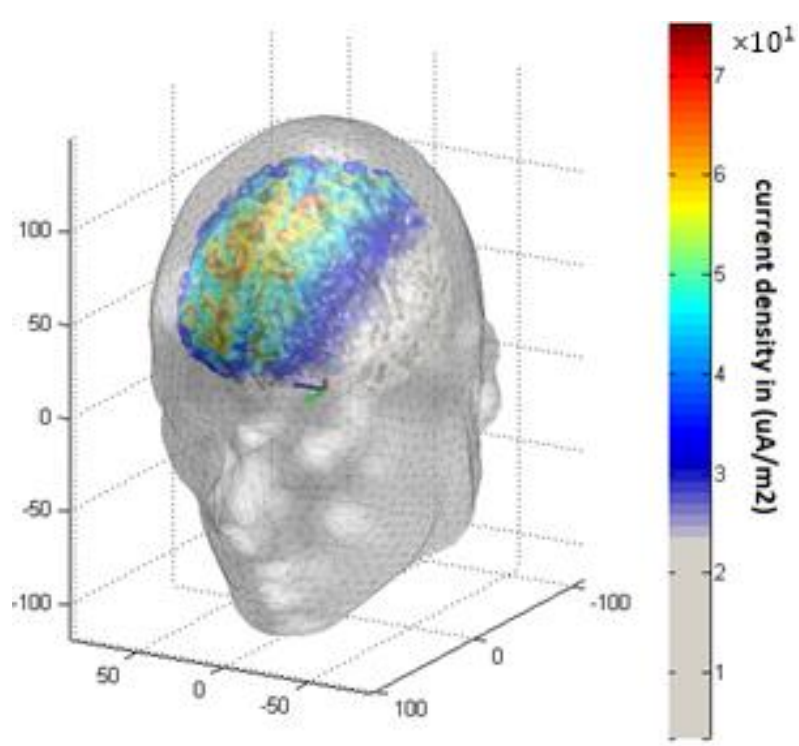

Fig. 17. Cortical current density distribution of low height tower

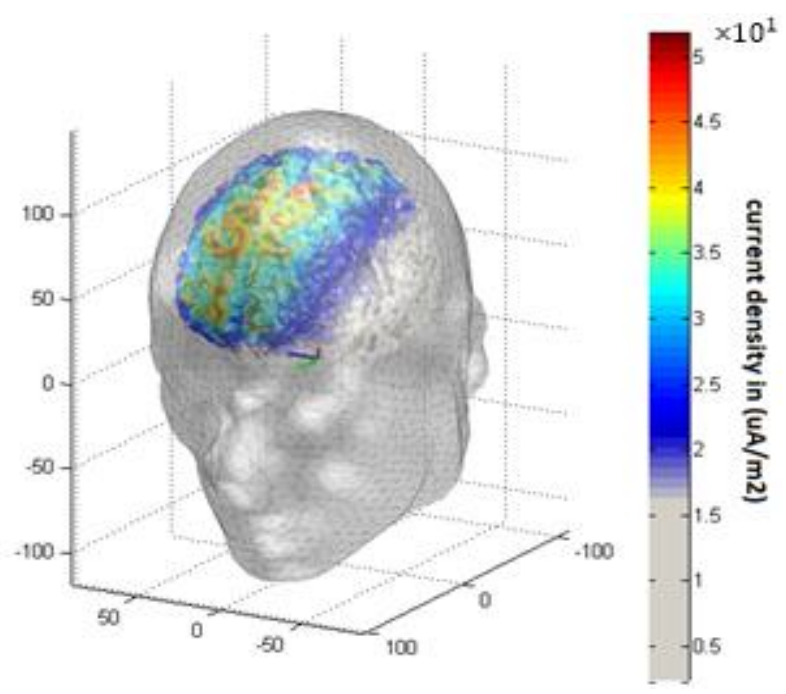

Fig. 18. Cortical current density distribution of new pylon

\section{References}

[1] G. Kulkarni and Dr.W.Z.Gandhare, "Proximity Effects of High Voltage Transmission Lines on Humans", ACEEE Int. J. on Electrical and Power Engineering, vol. 03, no. 01, Feb 2012. 
[2] Lemer. E.J. "Biological effects of electromagnetic field," IEEE Spectrum, vol. 21, pp. 57-69, 1984.

[3] C. Garrido, A. F. Otero, J. Cidras, "Low-frequency magnetic fields fromelectrical appliances and power lines," IEEE Trans. Pow. Delivery, vol. 18, no. 4, pp. 1310-1319, October 2003.

[4] J. Mokoena, P. H. Pretorius, P. T. Bhulose, A. A. Burger, D. Muftic, "Electric and magnetic field limits applied to overhead power line design in South Africa", Inter. Coll. - Pow. Freq. Electro. Fields ELF EMF, paper 11, Sarajevo, 2009.

[5] R. Cruz, L. A. Dominques, A. M. Neto, C. R. Barbosa, T. Dovan, "Analysis of electromagnetic fields exposure limits from International Standards-Application of computational modelling to assess human exposure to EMF," Inter. Coll. - Pow. Freq. Electro. Fields ELF EMF, paper 5, Sarajevo, 2009.

[6] CIGRE C4.205, "Characterisation of ELF magnetic fields", CIGRE Tech. Brochure, no. 21, 1980.

[7] Council recommendation on the limitation of exposure of the general public to electromagnetic fields $0 \mathrm{~Hz}-$ $300 \mathrm{GHz}, 2188^{\mathrm{a}}$ reunião doconselho da União Europeia, Junho 1999.

[8] ERRI, Transmission line reference book $345 \mathrm{kV}$ and above, Fred Weidner and Sons, New York, NY, 1975.

[9] Deno, D. W. and L. E. Za®anella, "Electrostatic e®ects of overhead transmission lines and stations", Electric Power Research Institute, Palo Alto, Calif, 1975.

[10] R. N. W. Group, "A survey of methods for calculating transmission line conductor surface voltage gradient", IEEE Trans. vol.pas-98, no.6, Nov. /Dec 1979.

[11] R. M. Sarmento, "Electric and magnetic fields in overhead power transmission lines", IEEE Trans. vol.10, no. 4, June 2012.

[12] H. Singer, H. Steinbigler, P. Weiss, "A charge simulation method for the calculation of high voltage fields", IEEE Trans., vol. pas-93, pp. 1660-1668, January 1974.

[13] "Environmental statement project need and alternatives", Appendix 2k, document 2.6-5.2, May 2014 from http://infrastructure.planningportal.gov.uk

[14] S. Norasmah Mohtar, M.N Jamal, and M.Sulaiman, "Analysis of all Aluminum Conductor (AAC) and All Aluminum Alloy Conductor (AAAC)", IEEE, 2004.

[15] Oman Cables industry (SAOG), "Overhead line conductors, OCI/PB OHL/REV.001/010311.

[16] R. Djekidel, "Optimum phase configuration and location of the aerial pipeline in the vicinity of a high voltage overhead line", Periodica Polytechnica Electrical Engineering and Computer Science), pp. 143-150, mar 2016.

[17] M. Luwen xu, Y. Li, J. Yu, X. Hou, Ch. An, "Research on Electric Field of High-Voltage Transmission Line Power Frequency", IEEE, china, Oct 2006.

[18] A. A. Ponnle, K. B. Adedeji, B. T. Abe, A. A. Jimoh, "Planar magnetic field distribution underneath twocircuit linear configured power lines in various phase arrangements", IEEE, Ethiopia, Sep 2015.

[19] E. Hojjati Najafabadi, S. M. Barakati, S. Tavakoli Afshar, "Optimal Determination of Generation and FACTS Devices Location/Size for Congestion Elimination", Journal of Iranian Association of Electrical and Electronics Engineers, vol. 12,no. 1, pp. 125-138, 2015.
[20] M. A. Golkar, S. Hosseinzadeh, A. Hajizadeh, "Optimal multi-objective planning of distribution system with distributed generation", Journal of Iranian Association of Electrical and Electronics Engineers, vol. 5,no. 2, pp. 4148, 2008.

[21] K. Deb, A. Pratap, S. Agarwal, T. Meyarivan, "A Fast and Elitist Multiobjective Genetic Algorithm: NSGA-II," Evol. Computation, vol. 6, no. 2, pp. 182-197, 2002.

[22] K. Deželak, G. Štumberger, F. Jakl, “Arrangements of overhead power line conductors determined by differential evolution", HRO CIGRE, Cavtat, 2009.

[23] K.De`zelak, F.Jakl, G. `Stumberger, "Arrangements of overhead power line phase conductors obtained by differential evolution", Elsevier, August 2011.

[24] IEC 60826, "Design criteria of overheadline transmission lines", 4rd ed., 2017.

[25] J.-M. Jin The finite element method in electromagnetics. 2nd Ed. New York: John Wiley \& Sons, 2002.

[26] P. B. Zou, "Numerical analysis of electromagnetic fields", Springer-Verlag, Berlin, 1993.

[27] A. A. Hossam-Eldin, Kamilia Youssef and Hanna Karawia, "investigations of induced currents in human bodies due to exposure to emf from low voltage appliances", 11 inter Middle East power systems conference, Dec 2006.

[28] M. Trlep, A. Hamler, M. Jesenik, and B. ¡Stumberger, "Electric field distribution under transmission lines dependent on ground surface", IEEE Trans on magnetics vol. 45, no. 3, pp. 1748-1751, 2009.

[29] A. H. Eldin, W. Mokhtar, E. M .Ali, "Effect of electromagnetic fields from power lines on metallic objects and human bodies", IJAE, pp. 2(6):151-158, alexandria, 2012.

[30] A. Antal, T.Z. Kincses, M.A. Nitsche, O. Bartfai, W. Paulus, "Excitability changes induced in the human primary visual cortex by transcranial direct current stimulation: direct electrophysiological evidence", Elsevier. Invest Ophthalmol Vis Sci, pp. 45:702-7, Feb 2004.

[31] F. Fregni, P.S. Boggio, M. Nitsche, Pascual-Leone A, "Transcranial direct current stimulation", Elsevier. Brit J Psychiat, pp. 186:446-7, May 2005.

[32] M. A. Nitsche, S. Doemkes, T. Karakose, A. Antal, Liebetanz D, Lang N, Tergau F, Paulus W, "Shaping the effects of transcranial direct current stimulation of the human motor cortex", Elsevier. J Neurophysiol, Apr 2007.

[33] J. A. Williams, M. Imamura, F. Fregni, "Updates on the use of noninvasive brain stimulation in physical and rehabilitation medicine", Elsevier. J Rehabil Med, pp. 41:305-11, Apr 2009.

[34] P.C .Miranda, M. Lomarev, M. Hallett, "Modeling the current distribution during transcranial direct current stimulation", Elsevier. J ClinNeurophysiol, pp. 117:1623-9, Jul 2006.

[35] 14- K. Deb, A. Pratap, S. Agarwal, T. Meyarivan, "A fast and elitist multiobjective genetic algorithm: NSGAII", IEEE Trans. Evolutionary Computation, vol.6, pp. 182-197, Apr 2002.

[36] S. S. Salas, A. G. Fonseca, F. A. Guerra, R. Solera, "Multi-objective optimization of electromagnetic fields from urban overhead power lines", IEEE. Colombia, Nov 2014. 